\title{
Update on angiotensin II: new endocrine connections between the brain, adrenal glands and the cardiovascular system
}

\author{
Frans H H Leenen', Mordecai P Blaustein ${ }^{2,3}$ and John M Hamlyn² \\ ${ }^{1}$ Brain and Heart Research Group, University of Ottawa Heart Institute, Ottawa, Ontario, Canada \\ 2Department of Physiology, University of Maryland School of Medicine, Baltimore, Maryland, USA \\ ${ }^{3}$ Department of Medicine, University of Maryland School of Medicine, Baltimore, Maryland, USA
}

Correspondence

should be addressed

to $\mathrm{F} \mathrm{H} \mathrm{H}$ Leenen

Email

fleenen@ottawaheart.ca

\begin{abstract}
In the brain, angiotensinergic pathways play a major role in chronic regulation of cardiovascular and electrolyte homeostasis. Increases in plasma angiotensin II (Ang II), aldosterone, $\left[\mathrm{Na}^{+}\right]$and cytokines can directly activate these pathways. Chronically, these stimuli also activate a slow neuromodulatory pathway involving local aldosterone, mineralocorticoid receptors (MRs), epithelial sodium channels and endogenous ouabain (EO). This pathway increases $A T_{1} R$ and NADPH oxidase subunits and maintains/further increases the activity of angiotensinergic pathways. These brain pathways not only increase the setpoint of sympathetic activity per se, but also enhance its effectiveness by increasing plasma EO and EO-dependent reprogramming of arterial and cardiac function. Blockade of any step in this slow pathway or of $A T_{1} R$ prevents Ang II-, aldosterone- or salt and renal injury-induced forms of hypertension. MR/AT ${ }_{1} R$ activation in the CNS also contributes to the activation of sympathetic activity, the circulatory and cardiac RAAS and increase in circulating cytokines in HF post MI. Chronic central infusion of an aldosterone synthase inhibitor, MR blocker or AT ${ }_{1} \mathrm{R}$ blocker prevents a major part of the structural remodeling of the heart and the decrease in LV function post MI, indicating that MR activation in the CNS post MI depends on aldosterone, locally produced in the CNS. Thus, Ang II, aldosterone and EO are not simply circulating hormones that act on the CNS but rather they are also paracrine neurohormones, locally produced in the CNS, that exert powerful effects in key CNS pathways involved in the long-term control of sympathetic and neuro-endocrine function and cardiovascular homeostasis.
\end{abstract}

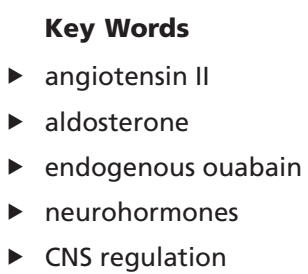

Endocrine Connections (2017) 6, R131-R145

\section{Introduction}

The classical view of the role of the central nervous system (CNS) in the regulation of the cardiovascular homeostasis focuses on the critical importance of the CNS in the acute, short-term control. In this paradigm, a variety of reflexes send afferent information to the brain and control sympathetic nerve traffic to arteries and veins, heart and kidneys. According to the Guytonian view of the circulation, these reflexes reset and the CNS and sympathetic activity have only limited involvement in the chronic regulation of the cardiovascular homeostasis and are not involved in the setpoint of the blood pressure (BP). In the last two decades, it has become apparent that this concept is too narrow. Endocrine afferent and efferent connections to and from the brain can play a http://www.endocrineconnections.org DOI: 10.1530/EC-17-0161 (c) 2017 The authors Published by Bioscientifica Ltd

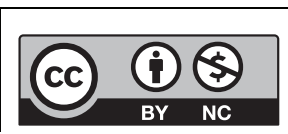

This work is licensed under a Creative Commons Attribution-NonCommercial 4.0 International License. 
powerful role in the long-term control of the circulation in, for example, heart failure and hypertension. In this brief review, we address only one aspect of these extensive endocrine interactions, i.e. the important new concept that angiotensin II (Ang II), aldosterone and endogenous ouabain (EO) are not simply circulating hormones that act on the CNS but rather that they are also paracrine neurohormones, locally produced in the CNS, that exert powerful effects in key CNS pathways involved in the long-term control of sympathetic and neuroendocrine function and the regulation of cardiovascular homeostasis. We will first provide an update on CNS angiotensinergic pathways, and then review the actions of plasma Ang II, aldosterone and EO mediated through these pathways. The next section reviews studies on the role of brain Ang II in the regulation of plasma aldosterone and EO, and effects of EO on arteries and the heart. We conclude with a review of recent studies on blockade of the CNS angiotensinergic pathways as a therapeutic strategy for treatment of hypertension and heart failure.

\section{CNS pathways contributing to long-term regulation of the circulation}

Daily living depends critically on the acute millisecondto-millisecond regulation by the CNS of sympathetic and parasympathetic nerve traffic to the heart and arteries. After release into the synaptic cleft, neurotransmitters such as glutamate or GABA bind to ligand-gated ionotropic receptors, which change their conformation and open their ion channels in less than a millisecond. The resulting ion currents can initiate neuronal membrane depolarization and generate high-speed action potentials along the axon, as well as subsequent repolarization. The effectiveness of this fast synaptic transmission can be influenced by a variety of mechanisms. For example, the quantity of neurotransmitter release from the presynaptic terminal in response to an action potential can be modulated. Also, the responsiveness of the post-synaptic neuron to a given amount of neurotransmitter can be altered by changing the number of receptors and/or the activity of intracellular signaling pathways (1). Such pre- and postsynaptic changes may blunt or enhance autonomic and cardiovascular responses. In general, however, autonomic activity will return quickly to its setpoint due to buffering mechanisms such as arterial baroreflex resetting. These glutamat-/GABA-ergic autonomic pathways are primarily intended for the acute regulation of autonomic tone.
Nonetheless, overcoming this resetting by chronic electrical stimulation of the carotid baroreceptors causes persistent decreases in sympathetic activity and BP (2). The resulting enhanced GABA-ergic inhibition lowers the setpoint for sympathetic tone but may also inhibit responsiveness to acute stresses.

In contrast, slow-acting CNS pathways involve signal transduction over seconds to minutes. In the case of angiotensinergic pathways, Ang II released into the synaptic cleft binds to angiotensin type 1 receptors $\left(\mathrm{AT}_{1} \mathrm{R}\right)$; this stimulates a G-protein signaling pathway, activates NADPH oxidases and increases intracellular reactive oxygen species (ROS) $(3,4)$. The increased ROS, by altering gene expression and other mechanisms, leads to the activation of presympathetic neurons that project to the intermediolateral cell column in the spinal cord (5, 6). Angiotensinergic pathways originate from neurons in circumventricular organs (CVOs) in the forebrain such as the subfornical organ (SFO) and the organum vasculosum of the lamina terminalis (OVLT). These CVOs are located outside the blood-brain barrier (BBB), and project to the paraventricular nucleus (PVN) in the hypothalamus and to the rostral ventrolateral medulla (RVLM) in the brainstem. Ang II-containing neuronal cell bodies and axonal endterminals are present in these major cardiovascular regulatory nuclei and $\mathrm{AT}_{1} \mathrm{R}$ are found on both pre- and post-synaptic terminals in these nuclei. Besides direct neuronal actions, Ang II/ $\mathrm{AT}_{1} \mathrm{R}$ can also activate microglia to generate proinflammatory cytokines, which in nuclei such as the PVN contribute to ROS production and downstream sympatho-excitatory and pressor responses $(7,8)$.

Active renin is almost undetectable in the brain. Recently, it has become apparent that instead, prorenin binds to the membrane prorenin receptor (PRR) and plays a major role in the local production of Ang II both in physiological and pathophysiological conditions such as hypertension $(9,10)$. Upon release into the synaptic cleft, Ang II (Ang 1-8) could directly bind to $\mathrm{AT}_{1} \mathrm{R}$, but in the brain Ang III (Ang 2-8) appears to act as the primary $\mathrm{AT}_{1} \mathrm{R}$ agonist $(11,12)$. High aminopeptidase A (APA) activity is present in hypothalamic and brainstem nuclei $(13,14)$, and Ang III, generated from Ang II by APA, may act as the main $\mathrm{AT}_{1} \mathrm{R}$ agonist of the brain RAS (15).

The above outlined angiotensinergic signaling pathways initiate sympatho-excitatory, neurohormonal and pressor responses to a variety of stimuli. These mechanisms, alone, are apparently not sufficient for persistent activation. Chronic s.c. infusion of Ang II 
increases the expression of immediate early genes (IEGs) in the SFO only for the first few days, but the increase is progressive and persistent in the supraoptic nucleus (SON) and magno- and parvocellular subdivisions of the PVN $(16,17)$. Similarly, ROS is markedly increased in the SFO at 7 days but no longer after 2 weeks, whereas ROS activation persists in the PVN and RVLM(4). These findings are consistent with the concept that Ang II/III induced $\mathrm{AT}_{1} \mathrm{R} / \mathrm{ROS}$ signaling is the primary driver for the increase in neuronal activity in the SFO/PVN/RVLM pathways, but that another, more slowly acting, signaling mechanism is also being activated that amplifies and maintains downstream responses. Several lines of evidence indicate that a slow-acting neuromodulatory pathway involving aldosterone, mineralocorticoid receptors (MR), epithelial sodium channels (ENaC), EO and its receptor, the $\alpha_{2} \mathrm{Na}^{+}$ pump, plays a critical role in this regard. All components of this pathway are present in hypothalamic nuclei such as the SFO, PVN and SON (5). These nuclei co-express MR $(18,19)$ and 11 -hydroxysteroid dehydrogenase type $2(11 \beta$-HSD2) $(18,20,21,22)$ or $11 \beta$-HSD type 1 (23), which both can confer aldosterone specificity to MRs (23). A variety of groups have demonstrated the presence in the hypothalamus of an ouabain-like factor. Aldosterone via MR increases the release of this factor from magnocellular neurons of the PVN and SON (24) for local action (25) or via the pituitary (26) release into the circulation. This brain factor appears to be identical to plasma EO $(27,28)$. In the brain, the ouabain-sensitive $\alpha_{3}$-isoform of $\mathrm{Na}^{+}, \mathrm{K}^{+}$-ATPase is highly expressed in neurons, and the ouabain-sensitive $\alpha_{2}$-isoform is the isoform in glia (29). Unexpectedly, in mice with an ouabain-resistant $\alpha_{2}$-isoform $\left(\alpha_{2}{ }^{\mathrm{R} / \mathrm{R}}\right)$, pressor responses to central infusion of ouabain or sodium (acting by release of EO) are largely absent $(30,31)$. This finding suggests that ouabain or EO may act mainly on glia rather than neurons in the CNS.

Aldosterone, acting though this slow neuromodulatory pathway, increases mRNA and protein expression of ACE, $\mathrm{AT}_{1} \mathrm{R}$ and NADPH oxidase subunits (25) and elevates intracellular superoxide levels and $\mathrm{Ca}^{2+}$ influx $(32,33)$. Aldosterone can, thereby, enhance Ang II release and $\mathrm{AT}_{1} \mathrm{R}$ signaling in, for example, the SFO (34) and the PVN (25). Consistent with this concept, central infusion of aldosterone or ouabain causes a gradual increase in sympathetic nerve activity (SNA), BP and heart rate that can be prevented by central infusion of an $\mathrm{AT}_{1} \mathrm{R}$ blocker $(32,35)$. Finally, and most importantly, central infusion of Ang II at a low rate (not effective when infused peripherally) increases hypothalamic aldosterone 2-to 3 -fold; this increase can be prevented by central infusion of an aldosterone synthase (AS) inhibitor. Moreover, when combined with central infusion of an AS inhibitor or MR blocker, central Ang II only causes a transient increase in BP rather than persistent hypertension (36). Together, these findings suggest that aldosterone, produced locally in the CNS, acts on MR in, for example, the SON or PVN, and via this neuromodulatory mechanism causes persistent activation of angiotensinergic sympathohumoral pathways.

\section{CNS actions of circulating Ang II, aldosterone and EO}

The CNS actions of Ang II, aldosterone and EO are often overlooked and/or not integrated with the peripheral actions. The relative role of these different actions is still being debated and may depend on the disease model or the extent of the increase in plasma levels. In a recent 'state-of-the-art' article (37), we reviewed the accumulating evidence that, at modest increases in plasma levels, the CNS actions can play a critical role, with peripheral actions of the same hormones acting as important amplifiers. Newer studies have provided additional support for these CNS actions (Fig. 1).

\section{Plasma Ang II}

Chronic small increases in plasma Ang II by s.c. infusion gradually increase BP by up to $60 \mathrm{mmHg}$ (17), associated with an increase in neuronal $\mathrm{AT}_{1} \mathrm{R}$ and IEG expression, and in ROS in hypothalamic and brainstem nuclei $(4,17)$. Knockdown of $\mathrm{AT}_{1} \mathrm{R}$ specifically in the SFO prevents the increase in $\mathrm{AT}_{1} \mathrm{R}$ in the PVN and of ROS in the PVN and RVLM. Knockdown of $\mathrm{AT}_{1} \mathrm{R}$ or of NADPH oxidase in the SFO also prevents circulating Ang II-induced hypertension in rats or mice $(4,38)$. Activation of angiotensinergic projections from the SFO to the PVN appears critical in this regard, because knockdown of $\mathrm{AT}_{1} \mathrm{R}$ in the PVN also prevents the Ang II induced hypertension (39), and infusion of an $\mathrm{AT}_{1} \mathrm{R}$-blocker in the $\mathrm{PVN}$ reverses the hypertension (40). These findings indicate that circulating Ang II increases $\mathrm{AT}_{1} \mathrm{R} / \mathrm{ROS}$ in the $\mathrm{SFO}$, followed by $\mathrm{AT}_{1} \mathrm{R} / \mathrm{ROS}$ activation in the PVN, presumably by locally produced Ang II. Activation of this angiotensinergic pathway appears essential for the circulating Ang II-induced hypertension. 


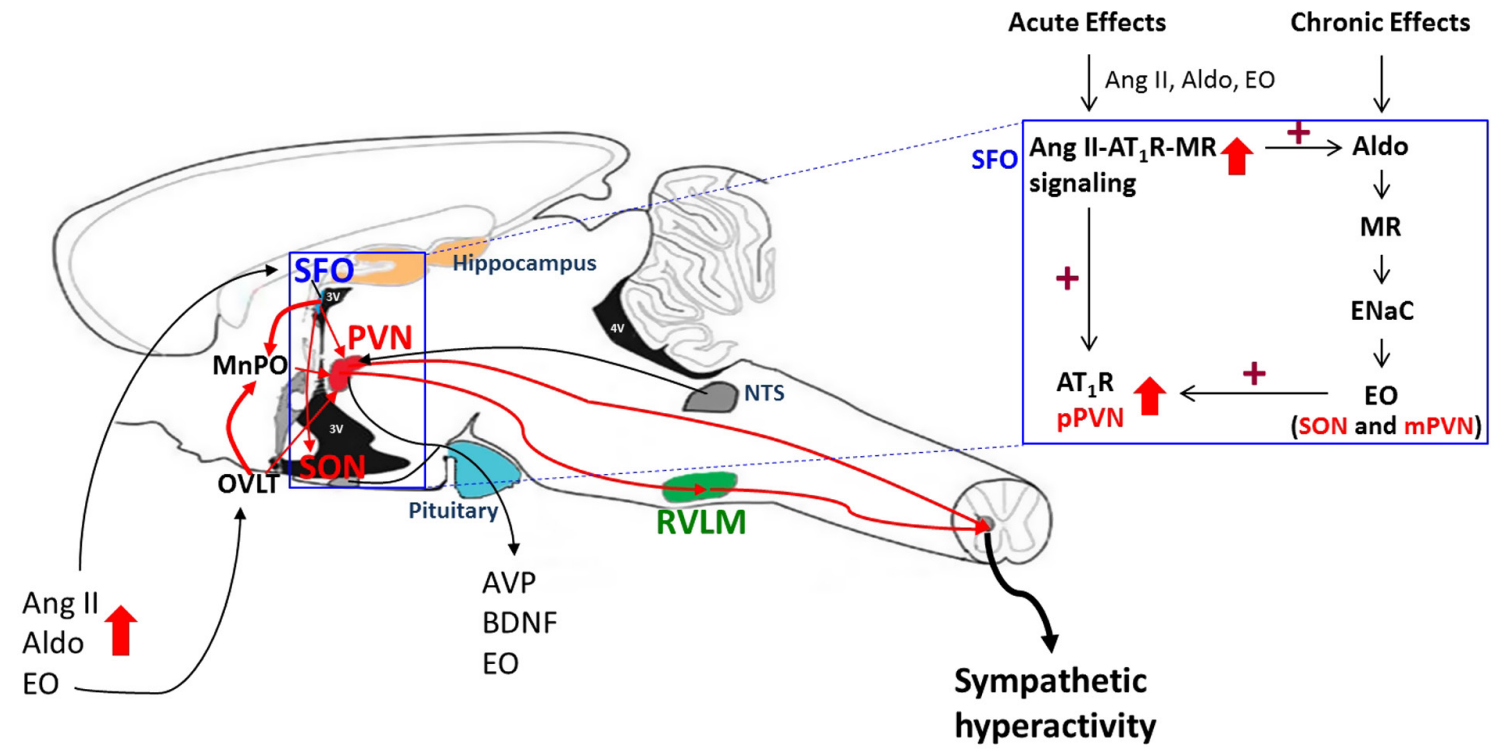

\section{Figure 1}

Acute and chronic effects of plasma Ang II, aldosterone and EO on brain angiotensinergic pathways. Circulating Ang II, aldosterone or EO can activate Ang II/AT ${ }_{1}$ R/ROS signaling in circumventricular organs such as the SFO and OVLT, which are located outside of the BBB, followed by activation of angiotensinergic projections to the PVN, SON and RVLM (red lines). Prolonged stimulation of AT ${ }_{1}$ R/MR in the SFO also activates a slow neuromodulatory pathway in the hypothalamus (box at upper right) that involves locally produced aldosterone, which binds MR in, for example, SON and PVN and, via ENaC increases hypothalamic EO. Ouabain or EO acutely inhibits $\alpha_{2} \mathrm{Na}^{+}$pumps and, chronically, also activates an $\alpha_{2} \mathrm{Na}^{+}$pump-associated protein kinase cascade that increases the expression of $A C E, A T_{1} R$ and NADPH oxidase subunits. As a consequence, chronic Ang II/AT ${ }_{1}$ /ROS signaling is maintained/ enhanced. Effective sympathetic tone is increased by enhanced secretion of EO (see Figs 2 and 3). See text for references.

As observed for central infusion of Ang II (see above), persistent activation of $\mathrm{AT}_{1} \mathrm{R} / \mathrm{ROS}$ in the CNS by plasma Ang II also appears to depend on the stimulation of the aldosterone-MR-EO neuromodulatory pathway. Elevation of plasma Ang II by s.c. infusion increases both the expression of aldosterone synthase (AS) (22) and aldosterone levels (17) in the hypothalamus. Central infusion of an AS inhibitor prevents this increase in hypothalamic aldosterone without affecting the Ang II-induced increase in plasma aldosterone (17); this implies that plasma Ang II increases local production of aldosterone. Central infusion of an AS inhibitor or MR blocker also markedly attenuates the IEG activation in both the magnocellular (neurosecretory) and parvocellular (presympathetic) parts of the PVN (17). Thus, persistent PVN activation depends on aldosterone/MR signaling. Further supporting this concept, central AS/MR blockade fully prevents the gradual $\sim 20 \mathrm{mmHg}$ increase in BP induced by a low s.c. Ang II infusion rate, that does not cause a detectable increase in plasma Ang II levels. On the other hand, a higher rate of infusion, that raises plasma Ang II 3-fold, increases BP by $15-20 \mathrm{mmHg}$ within 1-2 days, and then gradually, by another $40-45 \mathrm{mmHg}$, over the next 1-2 weeks. Central AS/MR blockade does not affect the initial increase in BP, but does block the subsequent further increase (17). Central MR blockade also normalizes the $\mathrm{BP}$ and normalizes the enhanced $\mathrm{BP}$ decrease in response to $\mathrm{AT}_{1} \mathrm{R}$ blockade in the PVN of rats with established s.c. Ang II-induced hypertension (40). These patterns of change in the hypothalamus/ brainstem and in BP in response to central or circulating Ang II indicate that central aldosterone-MR signaling plays a critical role in the persistent activation of CNS angiotensinergic pathways and hypertension.

Recent studies have addressed where in the CNS these MR are located. Knockdown of either MR or $\mathrm{AT}_{1} \mathrm{R}$ in the SFO, by intra-SFO infusion of AAV-MR- or $\mathrm{AAV}-\mathrm{AT}_{1} \mathrm{R}$ siRNA, similarly prevents Ang II-induced increases in $\mathrm{AT}_{1} \mathrm{R}$ expression in the SFO, in ROS in the PVN and RVLM and most of the hypertension (4). Knockdown of either MR or $\mathrm{AT}_{1} \mathrm{R}$ in the PVN also prevents the s.c. Ang II-induced hypertension (39). These findings suggest that MR-AT ${ }_{1} \mathrm{R}$ cross-talk in the SFO represents a critical first step, and (in the PVN) an essential downstream step. Both steps are apparently required to maintain increased activity in the angiotensinergic pathways and for longterm control of cardiovascular homeostasis by plasma Ang II. An increase in plasma aldosterone may contribute to the MR activation in the SFO (22), whereas locally produced aldosterone (possibly in magnocellular neurons

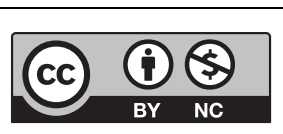

This work is licensed under a Creative Commons Attribution-NonCommercial 4.0 International License. 
in the SON and/or PVN) may, by volume transmission, be responsible for the MR activation in the PVN (17).

The above reviewed findings all indicate that activation of hypothalamic MR/AT ${ }_{1} \mathrm{R}$ signaling is essential for Ang II-induced hypertension, at least at small/modest increases in plasma Ang II. However, when comparing BP responses to central vs peripheral infusion of Ang II, it appears that these CNS actions per se are not sufficient for the progressive increase in BP caused by plasma Ang II. Central infusion of Ang II at a rate of $2.5 \mathrm{ng} / \mathrm{min}$ (well below peripheral rates) increases BP by $\sim 20 \mathrm{mmHg}$ within a day, but in contrast to s.c. Ang II, does not further increase BP over the subsequent days despite activating the same CNS mechanisms (36). This different pattern of BP responses suggests that the peripheral actions of plasma Ang II play an essential amplifier role for the CNS actions. The higher the plasma [Ang II], the more these peripheral actions on their own may be sufficient to cause severe hypertension. Indeed, in mice, the rapid development of s.c. Ang II-induced severe hypertension (+50-60 mmHg within 1-2 days) appears to depend solely on renal $\mathrm{AT}_{1} \mathrm{R}$ activation (41).

Further confounding the traditional view of the pre-eminence of the kidneys are studies on Ang II-high salt hypertension. A high salt diet markedly enhances the hypertensive response to chronic s.c. infusion of Ang II. For example, in rats on a 'regular' salt diet $(0.4 \%$ $\mathrm{NaCl}$ ), chronic s.c. infusion of Ang II at the low rate of $150 \mathrm{ng} / \mathrm{kg} / \mathrm{min}$ increases BP by $15-20 \mathrm{mmHg}$ after 8-10 days, but in rats on $2.0 \%$ high salt diet, this dose increases BP by $\sim 50 \mathrm{mmHg}(42,43)$. In the classical paradigm, one might expect that this is a typical kidneydependent form of severe hypertension. In fact, however, CNS mechanisms play a critical role, and as in the case for Ang II alone, MR/ENaC/AT $\mathrm{R}_{1}$ signaling $(43,44)$ and the PVN $(45,46)$ are involved.

\section{Plasma aldosterone}

The well-known renal actions of aldosterone are important for the maintenance of sodium homeostasis and are often considered to be pivotal for aldosterone's role in hypertension or heart failure. In rodents on regular salt intake, s.c. infusion of aldosterone at low rates, that increase plasma levels 2-3 fold, does not, alone, elevate BP (22), but when combined with high salt intake gradually raises BP by $20-30 \mathrm{mmHg}$ over $2-3$ weeks $(22,47)$. Studies in adrenalectomized rats showed hypothalamic aldosterone levels parallel plasma aldosterone levels (48). In contrast, in intact rats, circulating aldosterone poorly penetrates most brain areas protected by the BBB, and chronic infusion of aldosterone at rates that increase plasma aldosterone 5- to 8-fold cause only a minimal increase in hypothalamic aldosterone (17). Substantial competition by corticosterone for both uptake and binding to MR in the cell (49) may explain this different penetration pattern. However, circulating aldosterone can readily access neurons in brain nuclei outside the BBB, such as the SFO, which express both MR and ENaC (19). Aldosterone can enhance the Ang II-induced increase in intracellular $\mathrm{Ca}^{2+}$ in SFO neurons (33), and thereby activate downstream angiotensinergic pathways. Indeed, lesioning of the SFO prevents $60 \%-70 \%$ of the hypertension induced by aldosterone salt (22), as does central infusion of an $\mathrm{AT}_{1} \mathrm{R}$ blocker (47). Not surprisingly then, central infusion of an MR blocker is similarly effective $(22,47)$, but, unexpectedly, central infusion of an AS inhibitor is as effective (22). This suggests that circulating aldosterone, like Ang II, activates central angiotensinergic pathways involving local production of aldosterone. These pathways appear to project from the SFO to the PVN since knockdown of either $\mathrm{AT}_{1} \mathrm{R}$ or $\mathrm{MR}$ in the PVN also prevents most of the hypertension (22). Altogether, it appears that a modest increase in plasma aldosterone when combined with an increase in plasma $\left[\mathrm{Na}^{+}\right]$(induced by, e.g., 0.9\% saline drinking water), activates the aldosterone/MR/ENaC/EO neuromodulatory pathway via $\mathrm{MR} / \mathrm{AT}_{1} \mathrm{R}$ signaling in the SFO. This is critical for persistent Ang II/AT ${ }_{1} \mathrm{R}$ signaling in the PVN and, therefore, the hypertension.

The preceding studies employed direct central blockades to assess for CNS actions of plasma aldosterone. In humans and dogs, sympathetic activity often serves as an index for central actions of plasma aldosterone. Humans with primary hyperaldosteronism (PA) caused by an aldosterone-producing adenoma or adrenal hyperplasia have high plasma aldosterone levels and elevated BP. One study (50) reported that muscle sympathetic nerve activity (MSNA) was increased by about 30\% in a group of US patients with PA. Both MSNA and BP normalized after removal of the adenoma. In contrast, Japanese patients with PA exhibited a significantly reduced MSNA, and MSNA increased to normal after the removal of the adenoma (51). A variety of factors (50) may contribute to these opposite findings, including duration of aldosterone excess, extent of cardiac and renal fibrosis and damage by http://www.endocrineconnections.org DOI: 10.1530/EC-17-0161
(C) 2017 The authors Published by Bioscientifica Ltd
This work is licensed under a Creative Commons Attribution-NonCommercial 4.0 International License. 
the hypertension and aldosterone per se, and the level of salt intake. In a recent study in dogs (52), i.v. infusion of aldosterone and saline increased plasma aldosterone by 15 -fold, plasma $\mathrm{Na}^{+}$by $3 \mathrm{mM}$ and plasma vasopressin by 2 -fold and caused a marked drinking response. BP increased $\sim 20 \mathrm{mmHg}$ associated with a minor decrease in plasma norepinephrine (NE). Prolonged baroreflex activation similarly lowered plasma NE and heart rate before and after the induction of aldosterone-salt hypertension, but the BP fall was less: $-7 \pm 1$ vs $-16 \pm 2 \mathrm{mmHg}$ in control conditions. The authors concluded that sympathoexcitation does not contribute to the hypertension induced by mineralocorticoid excess. However, even if their conclusion is correct, this would not exclude central actions of plasma aldosterone on neuroendocrine outputs involved in cardiovascular regulation. Indeed, chronic central infusion of aldosterone in dogs increased TPR and elevated BP by $\sim 20 \mathrm{mmHg}$, but in contrast to studies in rats (32), did not increase plasma NE or heart rate (53). The authors suggested that release of a $\mathrm{Na}^{+}, \mathrm{K}^{+}$ATPase inhibitor from the hypothalamus could contribute to the increase in TPR and BP.

In summary, although CNS actions of aldosterone are well established, their contribution to the chronic cardiovascular effects of circulating aldosterone is still being debated. Species differences, modest vs large increases in plasma aldosterone and the level of salt intake may all be relevant factors in this regard.

\section{Plasma EO}

In 1991, a substance 'indistinguishable from ouabain' was identified by mass spectroscopy (MS) as an endogenous cardiotonic steroid (CTS) in human plasma (54). This discovery was validated by MS and NMR identification of EO in bovine, rodent and human plasma and tissue samples by laboratories on 3 continents $(26,27,55,56$, 57). A few investigators reported that they were unable to detect EO in human plasma (58), but none of these reports detailed how they attempted to separate EO by column chromatography prior to MS. A recent commentary provides a more in-depth review of this topic (28).

The adrenal glands are highly enriched with EO in humans, rodents and cattle $(54,56)$, and plasma EO is extremely low in adrenalectomized rats (54) and patients with adrenal insufficiency (59). Also, primary cultured bovine and human adrenocortical cells exhibit net synthesis of EO (60) and, in awake dogs, the adrenal venous $\mathrm{EO}$ concentration is 4 - to 5 -fold higher than that in the arterial blood (61). Thus, the adrenals are likely the primary source of circulating EO under normal conditions. In addition, there is evidence for local biosynthesis in the brain (see above). The extent to which brain EO contributes to the plasma levels is yet to be determined (26). The full EO biosynthetic pathway has not yet been elucidated. Nevertheless, EO, like aldosterone, is derived from progesterone but the distal steps are not yet known $(62,63)$. A related CTS, marinobufagenin (MBG), also has been linked to rodent hypertension $(64,65)$. MBG binds preferentially to rodent $\alpha_{1} \mathrm{Na}^{+}$pumps $(65,66)$, whereas EO favors the $\alpha_{2}$ and $\alpha_{3}$ isoforms.

Chronic increases in plasma EO or plant-derived ouabain activate multiple intracellular signaling pathways involved in cardiac and arterial function and remodeling $(67,68)$. CNS actions appear to play an important role as well. Several groups have shown that in rats chronic s.c. or i.v. infusion of ouabain causes a gradual, dose-dependent increase in BP, TPR and heart rate up to $40 \mathrm{mmHg}$ and $100 \mathrm{bpm}(69,70)$. Ouabain appears to initiate these CNS actions through the forebrain CVOs (71). Both the hypertension and the tachycardia can be prevented by central infusion of antibody Fab fragments raised against ouabain and can be reversed by acute ganglionic blockade. This suggests that central effects of ouabain increasing sympathetic tone play an essential role (70). Moreover, central infusion of an $\mathrm{AT}_{1} \mathrm{R}$ blocker prevents the sympatho-excitatory and pressor responses to both central and s.c. infusion of ouabain $(35,72)$, indicating that these responses to ouabain are mediated by $\mathrm{AT}_{1} \mathrm{R}$-dependent activation of angiotensinergic pathways in the CNS. Since the actions of ouabain appear to be glia dependent, and components of the RAS are also present in glia (73), this interaction may occur in glia rather than neurons, i.e. ouabain may increase Ang II release by glia cells, acting on $\mathrm{AT}_{1} \mathrm{R}$ in glia and/or neurons.

In conclusion, there is now compelling evidence that the CNS actions of plasma Ang II, aldosterone and EO play an important role in their cardiovascular effects. All of these effects depend on the activation of angiotensinergic pathways.

\section{Brain Ang II and neuroendocrine control of the circulation}

There is extensive literature on the regulation of the secretion of a number of hormones by CNS angiotensinergic pathways. In this section, we will 
focus on recent studies on the chronic effects of brain Ang II on plasma aldosterone and EO. Central infusion of Ang II at low rates $(2.5-12.5 \mathrm{ng} / \mathrm{min})$, that are not effective when infused peripherally, markedly increases plasma levels of aldosterone and corticosterone as well as EO (26, 36). s.c. infusion of Ang II at the rate of $150 \mathrm{ng} / \mathrm{kg} / \mathrm{min}$ does not cause detectable increases in plasma Ang II or the levels of these 3 steroids. When combined with high (2\%) salt diet (HS), however, this dose of Ang II causes severe hypertension associated with 2 - to 3 -fold increases in the plasma levels of all 3 steroids (74). Concomitant central infusion of an AS inhibitor or MR blocker prevents most of these increases $(26,36,74)$, indicating that central aldosterone-MR signaling is needed for these actions of central Ang II or peripheral Ang II-HS. ACTH release could be the link between the brain pathways and increased secretion of the 3 steroids by the adrenal cortex (60). However, ACTH tends to elevate plasma aldosterone only transiently and therefore seems unlikely to be the intermediary for chronic CNS Ang II actions (75). Alternative mechanisms include enhanced sympathetic drive to the adrenals (76), increases in plasma vasopressin (77) or direct adrenocortical effects of EO itself that stimulate aldosterone secretion (78). Low nanomolar concentrations of ouabain acutely stimulate basal and Ang II-evoked aldosterone secretion from bovine zona glomerulosa cells in primary culture. This stimulatory mechanism depends upon the ability of ouabain to raise intracellular $\mathrm{Ca}^{2+}$, augment the release of renin from the cells and, in the presence of angiotensinogen, to form locally high levels of Ang II (78). Moreover, in vivo, the chronic elevation of plasma ouabain into the range of 1.5-2.5 nM produced by s.c. infusion increases the mass of the adrenal glands, especially the zona glomerulosa layer, and elevates plasma aldosterone and corticosterone (79, 80) i.e., the same classical products of the rat adrenal zona glomerulosa layer that are augmented by brain Ang II. In addition, chronic active immunological neutralization of EO lowers plasma aldosterone ( $30 \%)$ in otherwise normal rats on a low salt intake (81). When taken together, these results are consistent with the following interpretations: (1) The brain, via circulating EO, can provide a physiologically relevant stimulus to zona glomerulosa function; (2) The elevation of brain Ang II augments the CNS production of EO, raises circulating EO and thereby stimulates the adrenal secretions of aldosterone and corticosterone. Collectively, the rodent work summarized in Fig. 2 implicates EO as the humoral intermediary that may link brain Ang II with augmented adrenal secretion of corticosteroids (Fig. 2).

The most evident readily observable consequences of chronically elevated brain Ang II in the rat can therefore be summarized as hypertension with co-elevated circulating EO and aldosterone. The obvious question concerns the broader clinical significance of these experimental observations. Are the latter humoral features present among some patients with hypertension? In a recent study involving 590 patients with never-treated mild-tomoderate essential hypertension, co-elevated circulating levels of EO and aldosterone were found in approximately

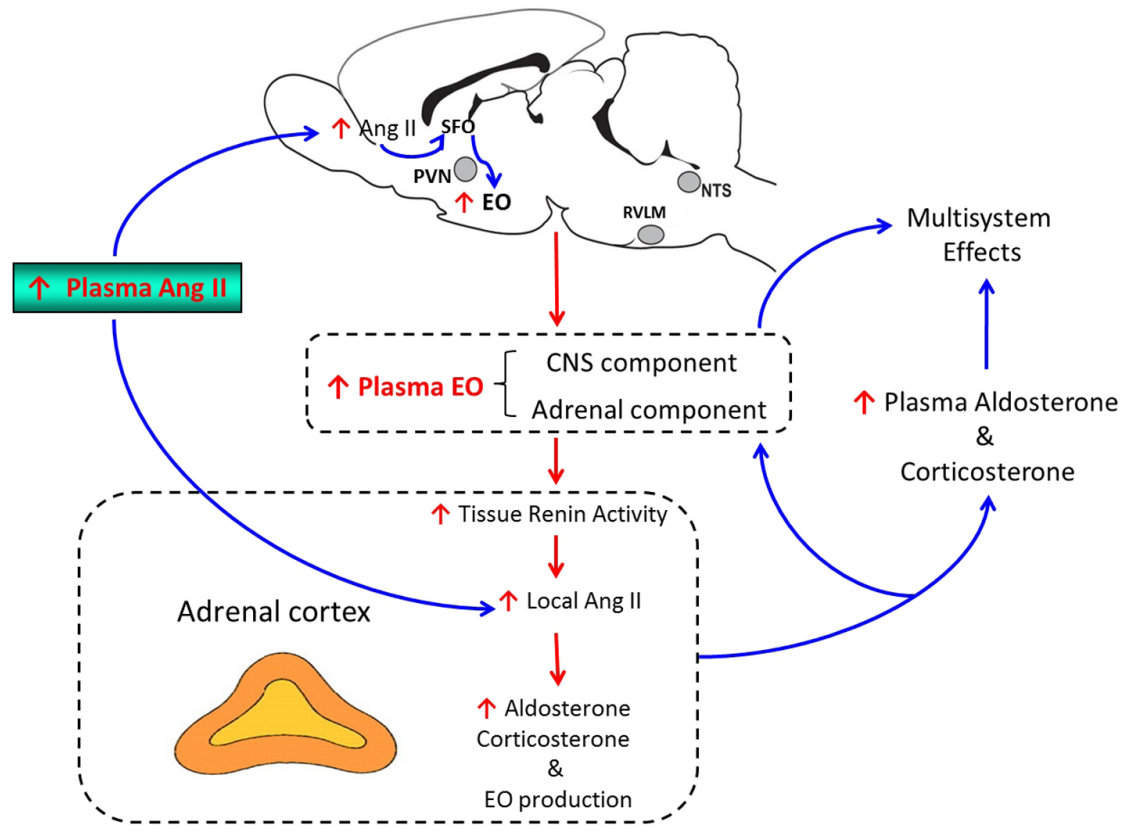

Figure 2

Proposed role of EO as a link between the effects of brain Ang II and adrenocortical activity. In response to the prolonged elevation of brain Ang II arising from either local or peripheral sources, a CNS aldosterone-MR-ENaC pathway (see Fig. 1) stimulates the production and secretion of CNS EO into the circulation. The elevated plasma EO, reflecting a (yet to be determined) variable mixture arising from CNS and adrenal sources, raises intracellular sodium and, via sodium-calcium exchange, augments $\mathrm{Ca}^{2+}$ signaling, stimulates intra-adrenal renin activity and enhances the local generation of Ang II. The combination of these actions leads to the enlargement of the zona glomerulosa layer and augmented adrenal production of aldosterone, corticosterone and EO. The stimulatory effects of Ang II on EO secretion from the CNS as well as intra-adrenal effects of EO involve $A T_{1} R$-mediated signaling. See text for references. http://www.endocrineconnections.org DOI: 10.1530/EC-17-0161 (c) 2017 The authors Published by Bioscientifica Ltd
This work is licensed under a Creative Commons Attribution-NonCommercial 4.0 International License. 
one-third of the patients (82). In addition, it has long been known that co-elevated levels of EO and aldosterone occur in $\sim 50 \%$ of patients with aldosterone-producing adrenal adenomas but, intriguingly, not among patients with hyperaldosteronism due to bilateral hyperplasia (83, 84, 85). Among the patients with unilateral adenomas, removal of the diseased gland normalized EO, aldosterone and BP (84). This suggests that, in these patients, the elevated EO originates primarily from the adrenal glands and that the co-elevation of EO and aldosterone are sufficient to drive the hypertension. Moreover, it may be recalled that circulating $\mathrm{EO}$ and aldosterone both have actions that activate brain Ang II pathways and that the central blockade of either of these agents prevents hypertension. This implies that the CNS is positioned as a critical component between adrenocortical hyperfunction and the elevated arterial tone and BP even in patients with adenoma producing hyperaldosteronism. Further, as EO is a stimulus to aldosterone secretion, the question arises as to whether in some patients, their zona glomerular adenomas might primarily hypersecrete EO and thereby evoke a secondary form of aldosterone excess (86). Irrespective of the primacy of aldosterone in hyperaldosteronism, the impact of elevated plasma levels of EO, aldosterone and corticosterone extends beyond their effects on BP; these steroids and their receptors have been implicated in cardiac growth and fibrosis, podocyte damage, memory and mood $(86,87,88,89$, $90,91)$. Thus, among those individuals in whom EO and aldosterone are inappropriately co-elevated, there may be a higher incidence of adverse cardiac, renal and CNS sequelae. Further mechanistic studies are clearly needed to elucidate the specific pathways through which the brain regulates and is influenced by the plasma levels of these important steroids.

\section{Direct effects of EO on the heart and arteries}

EO inhibits ouabain-sensitive cardiac $\mathrm{Na}^{+}$pumps and raises local intracellular $\mathrm{Na}^{+}\left(\left[\mathrm{Na}^{+}\right]_{\mathrm{i}}\right)$, thereby promoting net $\mathrm{Ca}^{2+}$ gain via $\mathrm{NCX}$ and enhancing cardiac $\mathrm{Ca}^{2+}$ signaling and contraction: the well-documented 'positive inotropic effect' (68). If sustained, this can foster cardiac hypertrophy (68). Similar mechanisms are responsible for the analogous vasotonic effect of $\mathrm{EO}$ in arteries $(68,92)$. This action may contribute (along with enhanced sympathetic drive) to the elevated total peripheral vascular resistance that is a hallmark of hypertension (93) (Fig. 3).

In addition to these $\mathrm{Na}^{+}$transport-dependent effects, sustained EO binding to $\mathrm{Na}^{+}$pumps has $\mathrm{Na}^{+}$ transport-independent, chronic tissue-specific actions that involve protein kinase (PK) cascade activation. This leads to changes in the expression (reprogramming) of $\mathrm{Ca}^{2+}$ transporters and other proteins $(94,95,96,97)$. In arteries, for example, EO-induced upregulation of $\mathrm{Na} / \mathrm{Ca}$ exchanger-1 (NCX1), sarcoplasmic reticulum $\mathrm{Ca}^{2+}$ pump-2 (SERCA2) and several $\mathrm{Ca}^{2+}$-permeable channels further promotes $\mathrm{Ca}^{2+}$ entry, vasoconstriction and hypertension $(68,94)$. In the heart, however, EO-induced PK activation upregulates NCX1, but downregulates SERCA2 expression; this fosters $\mathrm{Ca}^{2+}$ extrusion and attenuates $\mathrm{Ca}^{2+}$ signaling and contraction, thereby impairing systolic function (68). Note that the driving force on cardiac NCX1 favors $\mathrm{Ca}^{2+}$ efflux during diastole whereas, in arteries with tone, the myocyte plasma membrane is partially depolarized and the driving force on NCX1 favors $\mathrm{Ca}^{2+}$ influx (68). Both the chronic arterial and cardiac effects involve EO/ouabain-triggered activation of PK cascades (98, 99, $100,101,102,103)$. These can be stimulated by $\alpha_{1} \mathrm{Na}^{+}$ pumps when micromolar concentrations of CTS are used (101). However, in rodents nanomolar ouabain concentrations can activate these signaling pathways $(95,103)$. This implies that $\alpha_{2}$ and $\alpha_{3}$ pumps are the functionally relevant receptors in vivo for $\mathrm{EO}$ and is consistent with circulating levels of EO that range from $\sim 0.2$ to $1 \mathrm{nM}$.

Data from genetically engineered mouse models strongly support the view that the $\mathrm{EO}-\mathrm{Na}^{+}$pump endocrine system plays a pivotal role in cardiovascular function $(68,104)$. Normally ouabain-sensitive $\alpha_{2} \mathrm{Na}^{+}$ pumps (the EO receptors in cardiac muscle and vascular smooth muscle) can be made ouabain resistant without altering transport activity by mutating just two amino acids $(105,106)$. This attenuates or delays pressure overload-induced cardiac hypertrophy (107) and prevents several forms of hypertension $(105,106,107,108,109)$. Importantly, immuno-neutralization of EO has the same effects $(107,108)$. Furthermore, cardiac-specific knockout or overexpression of $\alpha_{2}$ pumps also delays or attenuates pressure overload-induced hypertrophy (110, 111). Clearly, the EO- $\alpha_{2} \mathrm{Na}^{+}$pump endocrine system, and not just myocyte stretch (112), contributes to the hypertrophy. http://www.endocrineconnections.org DOI: 10.1530/EC-17-0161 (c) 2017 The authors Published by Bioscientifica Ltd

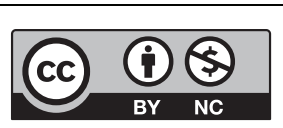

This work is licensed under a Creative Commons Attribution-NonCommercial 4.0 International License. 


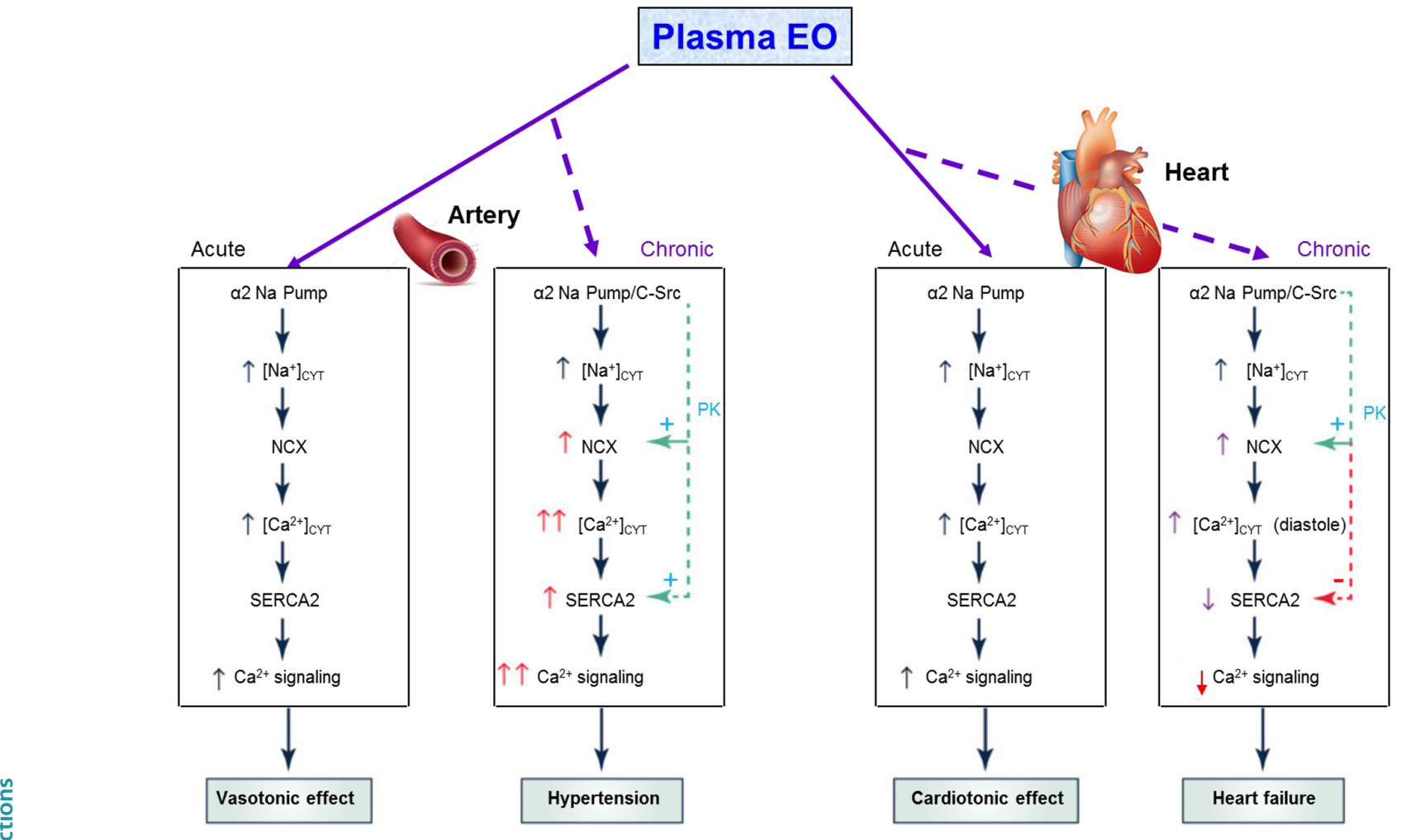

Figure 3

Acute and chronic effects of plasma EO on cardiac and arterial function The elevated plasma EO acutely inhibits $\alpha_{2} \mathrm{Na}^{+}$pumps in both the heart and arteries, and the rise in intracellular $\mathrm{Na}^{+}$rapidly induces $\mathrm{Na}^{+} / \mathrm{Ca}^{2+}$ exchanger (NCX)-mediated $\mathrm{Ca}^{2+}$ gain, and cardiotonic and vasotonic effects. Prolonged plasma EO elevation also activates an $\alpha_{2} \mathrm{Na}^{+}$pump-associated protein kinase cascade (e.g. C-Src-mediated) that increases cardiomyocyte and arterial smooth muscle cell NCX expression, and arterial sarcoplasmic reticulum (SR) $\mathrm{Ca}^{2+}$ pump (SERCA2) expression. In arteries with tone, NCX normally favors $\mathrm{Ca}^{2+}$ entry and helps to sustain cytosolic $\mathrm{Ca}^{2+}\left(\left[\mathrm{Ca}^{2+}\right]_{\mathrm{CYT}}\right)$ above contraction threshold. The EO-induced NCX and SERCA2 upregulation enhance Ca ${ }^{2+}$ signaling and SNA to increase vascular tone and elevate BP. In the heart, $\mathrm{NCX}$ promotes $\mathrm{Ca}^{2+}$ extrusion during diastole, but prolonged $\alpha_{2}$ pump inhibition by EO reduces the $\mathrm{Na}^{+}$gradient driving force so that $\left[\mathrm{Na}^{+}\right]_{\mathrm{CYT}}$ and diastolic $\left[\mathrm{Ca}^{2+}\right]_{\mathrm{CYT}}$ are both elevated; consequently, cardiac relaxation is slow and/or incomplete. Also, cardiac SERCA2 expression is usually reduced in heart failure (perhaps due to the high EO), as are SR $\mathrm{Ca}^{2+}$ stores and $\mathrm{Ca}^{2+}$ transients, and systolic function is impaired. See text for references. Reproduced, with permission, from Blaustein M, Chen L, Hamlyn J, Leenen FHH, Lingrel J, Wier W \& Zhang J, Pivotal role of $\alpha 2 \mathrm{Na}^{+}$pumps and their high affinity ouabain binding site in cardiovascular health and disease, Journal of Physiology, 2016, 594, 6079-6103. Copyright 2016 The Physiological Society.

\section{Therapeutic implications of brain angiotensinergic pathways for cardiovascular disease}

In addition to Ang II and aldosterone, plasma/CSF $\left[\mathrm{Na}^{+}\right]$and cytokine levels increase and activate brain angiotensinergic pathways in a variety of cardiovascular diseases. One may therefore anticipate that their CNS actions play a role in cardiovascular pathophysiology. Knockdown of for example $\mathrm{MR}$ or $\mathrm{AT}_{1} \mathrm{R}$ in specific brain nuclei or central infusions of blockers at low rates, that are ineffective peripherally, can be used to assess the overall role of CNS angiotensinergic signaling for the activation of peripheral mechanisms contributing to cardiovascular disease. This concept has so far mainly been employed to test for the role of CNS-activated peripheral mechanisms that contribute to hypertension or heart failure in animal models. (c) 2017 The authors Published by Bioscientifica Ltd

\section{Hypertension}

Using these approaches, many groups have shown that central $\mathrm{AT}_{1} \mathrm{R}$ signaling plays a pivotal role in both the development and maintenance of hypertension in a number of models including hypertension induced by renal 'injury'/dysfunction (reviewed in (37). For example, central blockade of the aldosterone/MR/ENaC-EO neuromodulatory pathway can prevent or reverse the hypertension in many models (37), demonstrating that these CNS pathways are a valid potential therapeutic target. The key question is whether peripheral (for example s.c. or oral) dosing can cause central blockade, not only in brain nuclei outside the $\mathrm{BBB}$, such as the SFO, but also in nuclei inside the BBB such as the PVN. Important factors in this regard are the lipophilicity of the specific drug (or active metabolite), drug dose and duration of dosing

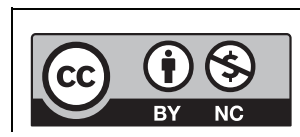

This work is licensed under a Creative Commons Attribution-NonCommercial 4.0 International License. 
(i.e., acute studies are not useful). Indeed, in rats, $\mathrm{AT}_{1} \mathrm{R}$ blockers, when administered in high enough doses, can cause marked and sustained $\mathrm{AT}_{1} \mathrm{R}$ blockade, not only in nuclei outside the BBB but also in important regulatory nuclei inside the barrier such as the PVN $(113,114)$. For example, in Dahl salt-sensitive (S) rats, central treatment with an $\mathrm{AT}_{1} \mathrm{R}$ blocker prevents salt-induced hypertension, and systemic treatment is similarly effective if the dose is high enough to cause sufficient central blockade (114, 115). These findings suggest that the degree of central and not peripheral $\mathrm{AT}_{1} \mathrm{R}$ blockade determines the extent of the antihypertensive effect in the Dahl model.

Studies in humans with hypertension on possible CNS effects of $\mathrm{AT}_{1} \mathrm{R}$ blockers evaluated the effects of conventional, 'clinically recommended' doses, e.g. losartan $50 \mathrm{mg} /$ day (116) or irbesartan $150 \mathrm{mg} /$ day (117). Neither study showed a decrease in the elevated resting sympathetic tone, assessed by MSNA or wholebody norepinephrine spillover. According to Krum and coworkers (116) 'reversal of sympathetic activation in hypertension cannot be expected with renin-angiotensin antagonism'. In contrast, Raheja and coworkers (117) considered the possibility that central $\mathrm{AT}_{1} \mathrm{R}$ may not have been inhibited, and that the results might have been different if a higher dose of irbesartan had been used. This concept has not yet been tested in patients with hypertension.

APA inhibitors are presently being tested in clinical studies as a new class of antihypertensive drugs to specifically target the brain RAS (118). RB150/QGC001 is a systemically active prodrug that crosses the $\mathrm{BBB}$ and is cleaved into 2 active EC33 molecules by brain reductases. Centrally administered EC33 or systemically administered RB150 similarly inhibit brain APA activity and lower BP in several experimental hypertension models $(119,120)$. The antihypertensive effectiveness of RB150 is presently being evaluated in patients with hypertension. The potential differences with standard systemic RAS blockade, for example, on renal function under different clinical conditions will need to be determined.

Experimental studies have shown that systemic treatment with an MR blocker at low-to-regular doses appears to be able to cause sufficient central MR blockade to lower sympathetic hyperactivity (121). In humans with hypertension, the sympathetic effects of MR blockers are distinctly different from those caused by chlorthalidone or hydrochlorothiazide. Treatment with chlorthalidone and spironolactone similarly lowered BP, but only chlorthalidone increased MSNA (122). In older hypertensives, treatment with hydrochlorothiazide or spironolactone similarly lowered BP, but only spironolactone lowered plasma norepinephrine (123). The increase in MSNA by chlorthalidone was fully prevented by concomitant treatment with spironolactone at $25 \mathrm{mg} /$ day (117). These findings suggest that the modest increase in plasma aldosterone by chlorthalidone appears sufficient to activate CNS MRs, which may mediate the sympathetic hyperactivity induced by chlorthalidone. Moreover, low doses of the MR blocker appear sufficient suggesting that the relevant MR population is readily accessible to spironolactone or its active metabolites.

\section{Heart failure}

In animal studies, central MR or $\mathrm{AT}_{1} \mathrm{R}$ blockade by central infusions of blockers or knockdown of $\mathrm{MR}$ or $\mathrm{AT}_{1} \mathrm{R}$ in specific nuclei such as the PVN inhibits the activation of several peripheral mechanisms, including sympathetic hyperactivity, that contribute to progressive cardiac dysfunction $(121,124,125,126,127)$. Systemic (oral or s.c.) treatment with $\mathrm{MR}$ or $\mathrm{AT}_{1} \mathrm{R}$ blockers also can inhibit the activation of the peripheral mechanisms (121, 126, 127). Central treatment with spironolactone at low doses and oral treatment with much higher doses have comparable beneficial effects on cardiac remodeling as well as dysfunction suggesting that CNS MR blockade by chronic oral treatment with spironolactone plays an important role (126). On the other hand, although central and systemic treatment with the $\mathrm{AT}_{1} \mathrm{R}$ blocker losartan similarly prevent sympathetic hyperactivity and improve cardiac fibrosis and LVEDP, only central treatment improves LV systolic function, whereas s.c. or oral losartan treatment further lowers LVPSP and $\mathrm{dP} / \mathrm{dt}_{\max }(127,128)$. Thus, peripheral $\mathrm{AT}_{1} \mathrm{R}$ blockade appears to exert an adverse effect on cardiac systolic function that overrides the positive effects of central $\mathrm{AT}_{1} \mathrm{R}$ blockade. The mechanisms contributing to this apparent adverse effect have not yet been elucidated, but may involve unopposed, enhanced cardiac $\mathrm{AT}_{2} \mathrm{R}$ activation (129) or blockade of Ang II-AT $\mathrm{R}$ signaling in myocytes, thereby decreasing $\mathrm{Ca}^{2+}$-influx and myocardial contractility (130). If cardiac $\mathrm{AT}_{1} \mathrm{R}$ blockade does exert adverse effects on cardiac systolic function in heart failure, then a new therapeutic approach is needed. For example, orally active APA inhibitors that specifically inhibit the activation of brain angiotensinergic pathways (34), may lead to more optimal and specific approaches to the prevention/management of heart failure after MI. In patients with heart failure such an approach may lower/normalize CNS-dependent activation of peripheral mechanisms contributing to heart failure progression.

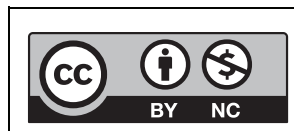

This work is licensed under a Creative Commons Attribution-NonCommercial 4.0 International License. 
Sympathetic hyperactivity could be prevented/reversed without interfering with the acute millisecond-tomillisecond sympathetic regulation of cardiovascular homeostasis and without causing nonspecific sympathoinhibition or nonspecific central sympatholysis, which may adversely affect outcome in patients with heart failure (131). Similarly, centrally induced decreases in plasma Ang II, aldosterone and EO would leave acute regulation intact and therefore may minimize adverse effects such as hypotension, hyperkalemia and renal dysfunction. Further preclinical and clinical studies are needed to assess whether orally active APA inhibitors are similarly effective in lowering SNA, but with less adverse effects and perhaps better cardiac outcomes.

\section{Conclusions}

The renal, cardiac and vascular actions of the endocrine, circulating RAAS play a major role in the short-term and chronic maintenance of the cardiovascular and electrolyte homeostasis. As a result, $\mathrm{AT}_{1} \mathrm{R}$ or MR blockade may lead to hypotension, renal dysfunction or hyperkalemia in, e.g., dehydration or low salt intake, or diseases such as heart failure or renal disease.

Plasma Ang II, aldosterone as well as EO (primarily via CVOs such as the SFO) also activate slow-acting CNS angiotensinergic pathways involved in cardiovascular regulation, e.g., by determining the setpoint of sympathetic activity without affecting its acute, secondto-second role. $\mathrm{AT}_{1} \mathrm{R}-\mathrm{ROS}$ signaling is the primary driver for neuronal activation in these pathways. Nevertheless, persistent activation depends on parallel gradual activation of a hypothalamic aldosterone/MR/ENaC/EO pathway, which increases the expression of key $\mathrm{AT}_{1} \mathrm{R}$ signaling components. These brain pathways appear to not only increase the setpoint of SNA per se, but also to enhance its effectiveness by increasing plasma EO and EO-dependent reprogramming of arterial and cardiac function. In contrast to peripheral blockades, blockade of central $\mathrm{AT}_{1} \mathrm{R}$-ROS signaling normalizes the activity of the peripheral pathways and maintains physiological regulation and function.

The general outline of these concepts has been established, but important aspects of the regulation of these central and peripheral modulatory pathways still need to be established. The therapeutic potential of inhibiting these pathways to normalize rather than block (components of) the sympathetic nervous system or the circulating RAAS is apparent, and results from preclinical studies are promising. However, new therapeutic drug strategies will be needed as well as comparative clinical studies for efficacy and adverse effects.

\section{Declaration of interest}

The authors declare that there is no conflict of interest that could be perceived as prejudicing the impartiality of this review.

\section{Funding}

This work did not receive any specific grant from any funding agency in the public, commercial, or not-for-profit sector. Research from the authors reviewed in this article was supported by operating grants from the Canadian Institutes of Health Research and Quantum Genomics, Paris, France (for FL), and from the American Heart Association (for MB).

\section{Acknowledgments}

This review integrates concepts discussed in more detail in recent reviews by the authors $(5,28,37,67,68)$. Frans Leenen holds the Pfizer Chair in Hypertension Research, an endowed chair supported by Pfizer Canada, University of Ottawa Heart Institute Foundation and Canadian Institutes of Health Research.

\section{References}

1 Greengard P. The neurobiology of slow synaptic transmission. Science 2001294 1024-1030. (doi:10.1126/science.294.5544.1024)

2 Lohmeier TE \& Iliescu R. Chronic lowering of blood pressure by carotid baroreflex activation: mechanisms and potential for hypertension therapy. Hypertension 201157 880-886. (doi:10.1161/ HYPERTENSIONAHA.108.119859)

3 Zimmerman MC, Lazartigues E, Sharma RV \& Davisson RL. Hypertension caused by angiotensin II infusion involves increased superoxide production in the central nervous system. Circulation Research 200495 210-216. (doi:10.1161/01.RES.0000135483. 12297.e4)

4 Wang HW, Huang B, White R, Chen A, Ahmad M \& Leenen FHH. Mineralocorticoid and angiotensin II type 1 receptors in the subfornical organ mediate angiotensin II: induced hypothalamic reactive oxygen species and hypertension. Neuroscience 2016329 112-121. (doi:10.1016/j.neuroscience.2016.04.050)

5 Gabor A \& Leenen FHH. Central neuromodulatory pathways regulating sympathetic activity in hypertension. Journal of Applied Physiology 2012113 1294-1303. (doi:10.1152/ japplphysiol.00553.2012)

6 Chan SHH \& Chan JYH. Angiotensin: generated reactive oxygen species in brain and pathogenesis of cardiovascular diseases. Antioxidants and Redox Signaling 201319 1074-1084. (doi:10.1089/ ars.2012.4585)

7 Shi P, Diez-Freire C, Jun JY, Qi Y, Katovich MJ, Li Q, Sriramula S Francis J, Sumners C \& Raizada MK. Brain microglial cytokines in neurogenic hypertension. Hypertension 201056 297-3030. (doi:10.1161/HYPERTENSIONAHA.110.150409)

8 Biancardi VC, Stranahan AM, Krause EG, de Kloet AD \& Stern JE. Cross talk between $\mathrm{AT}_{1}$ receptors and toll-like receptor 4 in microglia contributes to angiotensin II-derived ROS production in the hypothalamic paraventricular nucleus. American Journal of Physiology: Heart and Circulatory Physiology 2016310 H404-H415. (doi:10.1152/ ajpheart.00247.2015)
This work is licensed under a Creative Commons Attribution-NonCommercial 4.0 International License. 
9 Li W, Peng H, Cao T, Sato R, McDaniels SJ, Kobori H, Navar LG \& Feng Y. Brain-targeted (Pro) renin receptor knockdown attenuates angiotensin II-dependent hypertension. Hypertension 201259 1188-1194. (doi:10.1161/HYPERTENSIONAHA.111.190108)

$10 \mathrm{Xu}$ Q, Jensen DD, Peng H \& Feng Y. The critical role of the central nervous system (pro) renin receptor in regulating systemic blood pressure. Pharmacology and Therapeutics 2016164 126-134.

11 Wright JW, Tamura-Myers E, Wilson WL, Roques BP, LlorensCortes C, Speth RC \& Harding JW. Conversion of brain angiotensin II to angiotensin III is critical for pressor response in rats. American Journal of Physiology: Regulatory, Integrative and Comparative Physiology 2003284 R725-R733. (doi:10.1152/ajpregu.00326.2002)

12 Fournie-Zaluski MC, Fassot C, Valentin B, Djordjijevic D, Goazig A, Corvol P, Roques BP, Llorens-Cortes C \& Baulieu EE. Brain reninangiotensin system blockade by systemically active aminopeptidase A inhibitors: a potential treatment of salt-dependent hypertension. PNAS 2004101 7775-7780. (doi:10.1073/pnas.0402312101)

13 Zini S, Masdehors P, Lenkei Z, Fournie-Zaluski MC, Roques BP Corvol P \& Llorens-Cortes C. Aminopeptidase A distribution in rat brain nuclei and increased activity in spontaneously hypertensive rats. Neuroscience $1997 \mathbf{7 8}$ 1187-1193. (doi:10.1016/S03064522(96)00660-4)

14 De Mota N, Hurrioz X, Claperon C, Bodineau L, Fassot C, Roques BP, Palkovits $\mathrm{M} \&$ Llorens-Cortes C. Human brain aminopeptidase A: biochemical properties and distribution in brain nuclei. Journal of Neurochemistry $2008 \mathbf{1 0 6}$ 416-428. (doi:10.1111/j.14714159.2008.05402.x)

15 Zini S, Fournie-Zaluski MC, Chauvel E, Roques BP, Corvol P \& Llorens-Cortes C. Identification of metabolic pathways of brain angiotensin II and III using specific aminopeptidase inhibitors: predominant role of angiotensin III in the control of vasopressin release. PNAS 199693 11968-11973.

16 Davern PJ \& Head GA. Fos related antigen immunoreactivity after acute and chronic angiotensin II-induced hypertension in the rabbit brain. Hypertension 200749 1170-1177. (doi:10.1161/ HYPERTENSIONAHA.106.086322)

17 Huang BS, Ahmadi S, Ahmad M, White RA \& Leenen FHH. Central neuronal activation and pressor responses induced by circulating Ang II: role of the brain aldosterone-ouabain pathway. American Journal of Physiology: Heart and Circulatory 2010299 H422-H430. (doi:10.1152/ajpheart.00256.2010)

18 Wang HW, Amin MS, El-Shahat E, Huang BS, Tuana BS \& Leenen FH. Effects of central sodium on epithelial sodium channels in rat brain. American Journal of Physiology 2010299 R222-R233.

19 Amin MS, Wang HW, Reza E, Whitman SC, Tuana BS \& Leenen FHH. Distribution of epithelial sodium channels and mineralocorticoid receptors in cardiovascular regulatory centers in rat brain. American Journal of Physiology: Regulatory, Integrative and Comparative Physiology 2005289 R1787-R1797. (doi:10.1152/ajpregu.00063.2005)

20 Moisan MP, Seckl JR \& Edwards CR. 11 beta-Hydroxysteroid dehydrogenase bioactivity and messenger RNA expression in rat forebrain: localization in hypothalamus, hippocampus, and cortex. Endocrinology 1990127 1450-1455. (doi:10.1210/endo-127-3-1450)

21 Zhang ZH, Kang YM, Yu Y, Wei SG, Schmidt TJ, Johnson AK \& Felder RB. 11beta-Hydroxysteroid dehydrogenase type 2 activity in hypothalamic paraventricular nucleus modulates sympathetic excitation. Hypertension 200648 127-133. (doi:10.1161/01. HYP.0000224296.96235.dd)

22 Wang HW, Huang B, Chen A, Ahmad M, White R \& Leenen F. Role of brain aldosterone and mineralocorticoid receptors in aldosterone-salt hypertension in rats. Neuroscience 2016314 90-105. (doi:10.1016/j.neuroscience.2015.11.055)

23 Chen J, Gomez-Sanchez CE, Penman A, May PJ \& Gomez-Sanchez E. Expression of mineralocorticoid and glucocorticoid receptors in preautonomic neurons of the rat paraventricular nucleus. American Journal of Physiology 2014306 R328-R340.
24 Yoshika M, Komiyama Y \& Takahashi H. An ouabain-like factor is secreted from immortalized hypothalamic cells in an aldosterone dependent manner. Neurochemistry International 201159 104-108. (doi:10.1016/j.neuint.2011.04.019)

25 Huang BS, Zheng, Tan J, Patel KP \& Leenen FHH. Regulation of hypothalamic renin-angiotensin system and oxidative stress by aldosterone. Experimental Physiology 201196 1028-1038. (doi:10.1113/expphysiol.2011.059840)

26 Hamlyn JM, Linde CI, Gao J, Huang BS, Golovina VA, Blaustein MP $\&$ Leenen FHH. Neuroendocrine humoral and vascular components in the pressor pathway for brain angiotensin II: a new axis in long term blood pressure control. PLoS ONE 20149 e108916. (doi:10.1371/journal.pone.0108916)

27 Kawamura A, Guo J, Itagaki Y, Bell C, Wang Y, Haupert GT Jr, Magil S, Gallagher RT, Berova N \& Nakanishi K. On the structure of endogenous ouabain. PNAS 199996 6654-6659. (doi:10.1073/ pnas.96.12.6654)

28 Hamlyn JM \& Blaustein MP. Endogenous ouabain: recent advances and controversies. Hypertension 201668 526-532. (doi:10.1161/ HYPERTENSIONAHA.116.06599)

29 Hieber V, Siegel GJ, Fink DJ, Beaty MW \& Mata M. Differential distribution of $\mathrm{Na}+\mathrm{K}+$-ATPase $\alpha$-isoforms in the central nervous system. Cellular and Molecular Neurobiology 199111 253-262. (doi:10.1007/BF00769038)

30 Van Huysse JW, Dostanic I, Lingrel JB, Hou X \& Wu H. Hypertension from chronic central sodium chloride in mice is mediated by the ouabain-binding site on the Na,K-ATPase $\alpha_{2}$-isoform. American Journal of Physiology: Heart and Circulatory Physiology 2011301 H2147-H2153. (doi:10.1152/ajpheart.01216.2010)

31 Leenen FH, Hou X, Wang HW \& Ahmad M. Enhanced expression of epithelial sodium channel causes salt-induced hypertension in mice through inhibition of the alpha2-isoform of $\mathrm{Na}+, \mathrm{K}+$ ATPase. Physiological Reports 20153 e12383. (doi:10.14814/ phy2.12383)

32 Zhang ZH, Yu Y, Kang YM, Wei SG \& Felder RB. Aldosterone acts centrally to increase brain renin-angiotensin system activity and oxidative stress in normal rats. American Journal of Physiology: Heart and Circulatory Physiology 2008294 H1067-H1074. (doi:10.1152/ ajpheart.01131.2007)

33 Xue B, Zhang Z, Roncari CF, Guo F \& Johnson AK. Aldosterone acting through the central nervous system sensitizes angiotensin II-induced hypertension. Hypertension 201260 1023-1030. (doi:10.1161/HYPERTENSIONAHA.112.196576)

34 Doris PA. Angiotensin II Immunoreactivity in push-pull perfusates from the paraventricular nucleus. Peptides 19889 481-485. (doi:10.1016/0196-9781(88)90151-9)

35 Huang BS \& Leenen FHH. Sympathoexcitatory pressor responses to increased brain sodium and ouabain are mediated via brain Ang II. American Journal of Physiology: Heart and Circulatory Physiology 1996 $270 \mathrm{H} 275-\mathrm{H} 280$

36 Huang BS, White RA, Ahmad M \& Leenen FHH. Role of brain corticosterone and aldosterone in central angiotensin II-induced hypertension. Hypertension 201362 564-571. (doi:10.1161/ HYPERTENSIONAHA.113.01557)

37 Leenen FH. Actions of circulating angiotensin II and aldosterone in the brain contributing to hypertension. American Journal of Hypertension 201427 1024-1032. (doi:10.1093/ajh/hpu066)

38 Lob HE, Schultz D, Marvar PJ, Davisson RL \& Harrison DG. Role of the NADPH oxidases in the subfornical organ in angiotensin II-induced hypertension. Hypertension 201361 382-387. (doi:10.1161/HYPERTENSIONAHA.111.00546)

39 Chen A, Huang BS, Ahmad M \& Leenen FHH. Knockdown of mineralocorticoid or angiotensin II type 1 receptor gene expression in the paraventricular nucleus prevents angiotensin II hypertension in rats. Journal of Physiology 2014592 3523-3536. (doi:10.1113/ jphysiol.2014.275560)

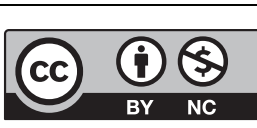


40 Gabor A \& Leenen FHH. Central mineralocorticoid receptors and the role of angiotensin II and glutamate in paraventricular nucleus of rats with angiotensin II-induced hypertension. Hypertension 201361 1083-1090. (doi:10.1161/HYPERTENSIONAHA.111.00797)

41 Crowley SD, Gurley SB, Herrera MJ, Ruiz P, Griffiths R, Kumar AP, Kim HS, Smithies O, Le TH \& Coffman TM. Angiotensin II causes hypertension and cardiac hypertrophy through its receptors in the kidney. PNAS 2006103 17985-17990. (doi:10.1073/pnas.0605545103)

42 King AJ \& Fink GD. Chronic low dose angiotensin II infusion increases venomotor tone by neurogenic mechanisms. Hypertension 200648 927-933. (doi:10.1161/01.HYP.0000243799.84573.f8)

43 Lu J, Wang HW, Ahmad M \& Leenen FH. Central mechanisms mediating angiotensin II-salt hypertension in rats. Hypertension 2015 66 AP250. (doi:10.1097/01.hjh.0000468116.28230.67)

44 Osborn JW, Olson DM, Guzman P, Toney GM \& Fink GD. The neurogenic phase of angiotensin II-salt hypertension is prevented by chronic intracerebroventricular administration of benzamil. Physiological Reports 20142 e00245.

45 Bardgett ME, Holbein W, Herrera-Rosales M \& Toney GM. Ang II-salt hypertension depends on neuronal activity in the hypothalamic paraventricular nucleus but not on local actions of tumor necrosis factor- $\alpha$. Hypertension 201463 527-534. (doi:10.1161/ HYPERTENSIONAHA.113.02429)

46 Larson RA, Gui L, Huber MJ, Chapp AD, Zhu J, LaGrange LP, Shan Z \& Chen QH. Sympathoexcitation in ang II-salt hypertension involves reduced SK channel function in the hypothalamic paraventricular nucleus. American Journal of Physiology: Heart and Circulatory Physiology 2015308 H1547-H1555. (doi:10.1152/ ajpheart.00832.2014)

47 Xue B, Beltz TG, Yu Y, Guo F, Gomez-Sanchez CE, Hay M \& Johnson AK. Central interactions of aldosterone and angiotensin II in aldosterone- and angiotensin II-induced hypertension. American Journal of Physiology: Heart and Circulatory Physiology 2011300 H555-H564. (doi:10.1152/ajpheart.00847.2010)

48 Yu Y, Wei SG, Zhang ZH, Gomez-Sanchez E, Weiss RM \& Felder RB. Does aldosterone upregulate the brain renin-angiotensin system in rats with heart failure? Hypertension 200851 727-733. (doi:10.1161/ HYPERTENSIONAHA.107.099796)

49 Yongue BG \& Roy EJ. Endogenous aldosterone and corticosterone in brain cell nuclei of adrenal-intact rats: regional distribution and effects of physiological variations in serum steroids. Brain Research 1987436 49-61. (doi:10.1016/0006-8993(87)91555-1)

50 Kontak AC, Wang Z, Arbique D, Adams-Huet B, Auchus RJ, Nesbitt SD, Victor RG \& Vongpatanasin W. Reversible sympathetic overactivity in hypertensive patients with primary aldosteronism. Journal of Clinical Endocrinology and Metabolism 201095 4756-4761. (doi:10.1210/jc.2010-0823)

51 Matsukawa T \& Miyamoto T. Does infusion of Ang II increase muscle sympathetic nerve activity in patients with primary aldosteronism? American Journal of Physiology: Regulatory, Integrative and Comparative Physiology 2008294 R1873-R1879. (doi:10.1152/ ajpregu.00471.2007)

52 Lohmeier TE, Liu B, Hildebrandt DA, Cates AW, Georgakopoulos D \& Irwin ED. Global and renal-specific sympathoinhibition in aldosterone hypertension. Hypertension 201565 1223-1230. (doi:10.1161/HYPERTENSIONAHA.115.05155)

53 Kageyama Y \& Bravo EL. Hypertensive mechanisms associated with centrally administered aldosterone in dogs. Hypertension 198811 750-753. (doi:10.1161/01.HYP.11.6.750)

54 Hamlyn JM, Blaustein MP, Bova S, Ducharme DW, Harris DW, Mandel F, Matthews WR \& Ludens JH. Identification and characterization of a ouabain-like compound from human plasma. PNAS 199188 6259-6263. (doi:10.1073/pnas.88.14.6259)

55 Komiyama Y, Nishimura N, Dong XH, Hirose S, Kosaka C, Masaki H, Masuda M \& Takahashi H. Liquid chromatography mass spectrometric analysis of ouabainlike factor in biological fluid.
Hypertension Research 200023 S21-S27. (doi:10.1291/hypres.23. Supplement_S21)

56 Schneider R, Wray V, Nimtz M, Lehmann WD, Kirch U, Antolovic $\mathrm{R} \&$ Schoner W. Bovine adrenals contain, in addition to ouabain, a second inhibitor of the sodium pump. Journal of Biological Chemistry 1998273 784-792. (doi:10.1074/jbc.273.2.784)

57 Tamura M, Harris TM, Phillips D, Blair IA, Wang YF, Hellerqvist CG, Lam SK \& Inagami T. Identification of two cardiac glycosides as $\mathrm{Na}(+)$-pump inhibitors in rat urine and diet. Journal of Biological Chemistry 1994269 11972-11979.

58 Lewis LK, Yandle TG, Hilton PJ, Jensen BP, Begg EJ \& Nicholls MG. Endogenous ouabain is not ouabain. Hypertension 201464 680-683. (doi:10.1161/HYPERTENSIONAHA.114.03919)

59 Sophocleous A, Elmatzoglou I \& Souvatzoglou A. Circulating endogenous digitalis-like factor(s) (EDLF) in man is derived from the adrenals and its secretion is ACTH-dependent. Journal of Endocrinological Investigation 200326 668-674. (doi:10.1007/ BF03347027)

60 Laredo J, Hamilton BP \& Hamlyn JM. Ouabain is secreted by bovine adrenocortical cells. Endocrinology 1994135 794-797. (doi:10.1210/ endo.135.2.8033829)

61 Boulanger BR, Lilly MP, Hamlyn JM, Laredo J, Shurtleff D \& Gann DS. Ouabain is secreted by the adrenal gland in awake dogs. American Journal of Physiology 1993264 E413-E419.

62 Hamlyn JM, Laredo J, Shah JR, Lu ZR \& Hamilton BP. 11-hydroxylation in the biosynthesis of endogenous ouabain: multiple implications. Annals of the New York Academy of Sciences 2003986 685-693. (doi:10.1111/j.1749-6632.2003.tb07283.x)

63 Perrin A, Brasmes B, Chambaz EM \& Defaye G. Bovine adrenocortical cells in culture synthesize an ouabain-like compound. Molecular and Cellular Endocrinology 1997126 7-15. (doi:10.1016/S03037207(96)03964-0)

64 Fedorova OV, Kolodkin NI, Agalakova NI, Lakatta EG \& Bagrov AY. Marinobufagenin, an endogenous alpha-1 sodium pump ligand, in hypertensive Dahl salt-sensitive rats. Hypertension 200137 462-466. (doi:10.1161/01.HYP.37.2.462)

65 Fedorova OV, Shapiro JI \& Bagrov AY. Endogenous cardiotonic steroids and salt-sensitive hypertension. Biochimica et Biophysica Acta 20101802 1230-1236. (doi:10.1016/j.bbadis.2010.03.011)

66 Wansapura AN, Lasko V, Xie Z, Fedorova OV, Bagrov AY, Lingrel JB \& Lorenz JN. Marinobufagenin enhances cardiac contractility in mice with ouabain-sensitive alpha $1 \mathrm{Na}+\mathrm{K}+-$ ATPase. American Journal of Physiology: Heart and Circulatory Physiology 2009296 H1833-H1839. (doi:10.1152/ajpheart.00285.2009)

67 Blaustein MP, Leenen FH, Chen L, Golovina VA \& Hamlyn JM. How $\mathrm{NaCI}$ raises blood pressure: a new paradigm for the pathogenesis of salt-dependent hypertension. American Journal of Physiology: Heart and Circulatory Physiology 2012302 H1031-H1049. (doi:10.1152/ ajpheart.00899.2011)

68 Blaustein M, Chen L, Hamlyn J, Leenen FHH, Lingrel J, Wier W \& Zhang J. Pivotal role of $\alpha 2 \mathrm{Na}^{+}$pumps and their high affinity ouabain binding site in cardiovascular health and disease. Journal of Physiology 2016594 6079-6103. (doi:10.1113/JP272419)

69 Yuan CM, Manunta P, Hamlyn JM, Chen S, Bohen E, Yeun J, Haddy FJ \& Pamnani MB. Long-term ouabain administration produces hypertension in rats. Hypertension 199322 178-187. (doi:10.1161/01. HYP.22.2.178)

70 Huang BS, Huang X, Harmsen E \& Leenen FHH. Chronic central versus peripheral ouabain, blood pressure and sympathetic activity in rats. Hypertension 199423 1097-1090.

71 Veerasingham SJ \& Leenen FHH. Ouabain- and central sodiuminduced hypertension depend on the ventral anteroventral third ventricle region. American Journal of Physiology: Heart and Circulatory Physiology 199945 H63-H70.

72 Huang BS \& Leenen FHH. Brain renin-angiotensin system and ouabain-induced sympathetic hyperactivity and hypertension

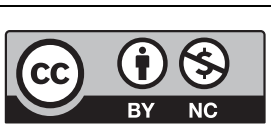

This work is licensed under a Creative Commons Attribution-NonCommercial 4.0 International License. 
in wistar rats. Hypertension 199934 107-112. (doi:10.1161/01. HYP.34.1.107)

73 Morimoto S, Cassell MD \& Sigmund CD. Glial- and neuronalspecific expression of the renin-angiotensin system in brain alters blood pressure, water intake, and salt preference. Journal of Biological Chemistry 2002277 33235-33241. (doi:10.1074/jbc.M204309200)

$74 \mathrm{Lu} \mathrm{J}$, Wang HW, Keshtkar-Jahromi M, Hamlyn JM \& Leenen FH. Central nervous system control of plasma aldosterone and endogenous ouabain in angiotensin II-salt hypertension. Hypertension 201566 AP249.

75 Holland $\mathrm{O} \&$ Carr B. Modulation of aldosterone synthase messenger ribonucleic acid levels by dietary sodium and potassium and by adrenocorticotrophin. Endocrinology 1993132 2666-2673. (doi:10.1210/endo.132.6.8389287)

76 Ehrhart-Bornstem M, Bornstein S, Gonzalez-Hernandez J, Holst JJ, Waterman M \& Scherbaum WA. Sympathoadrenal regulation of adrenocortical steroidogenesis. Endocrine Research 199521 13-24. (doi:10.3109/07435809509030417)

77 Payet N \& Lehoux JG. A comparative study of the role of vasopressin and ACTH in the regulation of growth and function of rat adrenal glands. Journal of Steroid Biochemistry 198012 461-467. (doi:10.1016/0022-4731(80)90307-6)

78 Tamura M, Piston DW, Tani M, Naruse M, Landon EJ \& Inagami T. Ouabain increases aldosterone release from bovine adrenal glomerulosa cells: role of renin-angiotensin system. American Journal of Physiology Endocrinology and Metabolism 1996270 E26-E35.

79 Manunta P, Rogowski Am Hamilton P \& Hamlyn JM. Ouabain-induced hypertension in the rat: relationships among plasma and tissue ouabain and blood pressure. Journal of Hypertension 199412 549-560.

80 Neri G, De Toni R, Tortorella C, Rebuffat P, Bova S, Cargnelli G Petrelli L, Spinazzi R \& Nussdorfer GG. Ouabain chronic infusion enhances the growth and steroidogenic capacity of rat adrenal zona glomerulosa: the possible involvement of the endothelin system. International Journal of Molecular Medicine 200618 315-319.

81 Yamada K, Goto A, Hui C \& Omata M. Role of ouabain-like compound in the regulation of plasma aldosterone concentration in rats. Life Sciences $1996 \mathbf{5 8} 1833-1837$.

82 Tentori S, Messaggio E, Brioni E, Casamassima N, Simonini M, Zagato L, Hamlyn JM, Manunta P \& Lanzani C. Endogenous ouabain and aldosterone are coelevated in the circulation of patients with essential hypertension. Journal of Hypertension 201634 2074-2080. (doi:10.1097/HJH.0000000000001042)

83 Masugi F, Ogihara T, Hasegawa T, Tomii A, Nagano M, Higashimori K, Kumahara K \& Terano Y. Circulating factor with ouabain-like immunoreactivity in patients with primary aldosteronism. Biochemical and Biophysical Research Communications 1986135 41-45. (doi:10.1016/0006-291X(86)90939-3)

84 Masugi F, Ogihara T, Hasegawa T, Sakaguchi K \& Kumahara Y. Normalization of high plasma level of ouabain-like immunoreactivity in primary aldosteronism after removal of adenoma. Journal of Human Hypertension 19882 17-20.

85 Rossi GP, Manunta P, Hamlyn J, Pavan E, De Toni R, Semlicini A \& Pessina AC. Immunoreactive endogenous ouabain in primary aldosteronism and essential hypertension: relationship with plasma renin, aldosterone and blood pressure levels. Journal of Hypertension 199513 1181-1191. (doi:10.1097/00004872199510000-00013)

86 Manunta P, Stella P, Rivera R, Ciurlino D, Cusi D, Ferrandi M, Hamlyn JM \& Bianchi G. Left ventricular mass, stroke volume, and ouabain-like factor in essential hypertension. Hypertension 199934 450-456. (doi:10.1161/01.HYP.34.3.450)

87 Pavlovic D. The role of cardiotonic steroids in the pathogenesis of cardiomyopathy in chronic kidney disease. Nephron Clinical Practice 2014128 11-21. (doi:10.1159/000363301)

88 Hamlyn JM \& Manunta P. Endogenous cardiotonic steroids in kidney failure: a review and hypothesis. Advances in Kidney Disease 201522 232-244. (doi:10.1053/j.ackd.2014.12.005)
89 Kvarta MD, Bradbrook KE, Dantrassy HM, Bailey AM \& Thompson SM. Corticosterone mediates the synaptic and behavioral effects of chronic stress at rat hippocampal temporoammonic synapses. Journal of Neurophysiology 2015114 1713-1724.

90 Gomez-Sanchez EP. Brain mineralocorticoid receptors in cognition and cardiovascular homeostasis. Steroid 201491 20-31. (doi:10.1016/j.steroids.2014.08.014)

91 Hodes A, Rosen H, Deutsch J, Lifschytz T, Einat H \& Lichtstein D. Endogenous cardiac steroids in animal models of mania. Bipolar Disorders 201618 451-459. (doi:10.1111/bdi.12413)

92 Blaustein MP, Juhaszova M \& Golovina VA. The cellular mechanism of action of cardiotonic steroids: a new hypothesis. Clinical and Experimental Hypertension 199820 691-703. (doi:10.3109/10641969809053247)

93 Zhang J, Hamlyn JM, Karashima E, Raina H, Mauban JR, Izuka M, Berra-Romani R, Zulian A, Wier WG \& Blaustein MP. Low-dose ouabain constricts small arteries from ouabain-hypertensive rats: implications for sustained elevation of vascular resistance. American Journal of Physiology: Heart and Circulatory Physiology 2009297 H1140-H1150. (doi:10.1152/ajpheart.00436.2009)

94 Pulina MV, Zulian A, Baryshnikov SG, Linde CI, Karashima E, Hamlyn JM, Ferrari P, Blaustein MP \& Golovina VA. Cross talk between plasma membrane $\mathrm{Na}(+) / \mathrm{Ca}(2+)$ exchanger-1 and TRPC/ Orai-containing channels: key players in arterial hypertension. Advances in Experimental Medicine and Biology 2013961 365-374.

95 Pulina MV, Zulian A, Berra-Romani R, Beskina O, Mazzocco-Spezzia A, Baryshnikov SG, Papparella I, Hamlyn JM, Blaustein MP \& Golovina VA. Upregulation of $\mathrm{Na}^{+}$and $\mathrm{Ca}^{2+}$ transporters in arterial smooth muscle from ouabain-induced hypertensive rats. American Journal of Physiology: Heart and Circulatory Physiology 2010298 H263-H274. (doi:10.1152/ajpheart.00784.2009)

96 Zulian A, Baryshnikov SG, Linde CI, Hamlyn JM, Ferrari P \& Golovina VA. Upregulation of $\mathrm{Na}^{+/} \mathrm{Ca}^{2+}$ exchanger and TRPC6 contributes to abnormal $\mathrm{Ca}^{2+}$ homeostasis in arterial smooth muscle cells from Milan hypertensive rats. American Journal of Physiology: Heart and Circulatory Physiology 2010299 H624-H633. (doi:10.1152/ ajpheart.00356.2010)

97 Zulian A, Linde CI, Pulina MV, Baryshnikov SG, Papparella I, Hamlyn JM \& Golovina VA. Activation of c-SRC underlies the differential effects of ouabain and digoxin on $\mathrm{Ca}^{2+}$ signaling in arterial smooth muscle cells. American Journal of Physiology: Cell Physiology $2013 \mathbf{3 0 4}$ C324-C333. (doi:10.1152/ajpcell.00337.2012)

98 Liu J, Tian J, Haas M, Shapiro JI, Askari A \& Xie Z. Ouabain interaction with cardiac $\mathrm{Na}+/ \mathrm{K}+$-ATPase initiates signal cascades independent of changes in intracellular $\mathrm{Na}^{+}$and $\mathrm{Ca}^{2+}$ concentrations. Journal of Biological Chemistry 2000275 27838-27844.

99 Liu L, Zhao X, Pierre SV \& Askari A. Association of P13K-Akt signaling apthway with digitalis-induced hypertrophy of cardiac myocytes. American Journal of Physiology: Cell Physiology 2007293 C1489-C1497. (doi:10.1152/ajpcell.00158.2007)

100 Mohammadi K, Kometiani P, Xie Z \& Askari A. Role of protein kinase $\mathrm{C}$ in the signal pathways that link $\mathrm{Na}+\mathrm{K}+-\mathrm{ATPase}$ to ERK1/2. Journal of Biological Chemistry 2001276 42050-42056. (doi:10.1074/jbc. M107892200)

101 Tian J \& Xie ZJ. The Na-K-ATPase and calcium-signaling microdomains. Physiology 200823 205-211. (doi:10.1152/ physiol.00008.2008)

102 Xie Z \& Askari A. Na+K+-ATPase as a signal transducer. European Journal of Biochemistry 2002269 2434-2439. (doi:10.1046/j.14321033.2002.02910.x)

103 Zulian A, Linde CI, Pulina MV, Baryshnikov SG, Papparella I, Hamlyn JM \& Golovina VA. Activation of c-SRC underlies the differential effects of ouabain and digoxin on $\mathrm{Ca}^{2+}$ signaling in arterial smooth muscle cells. American Journal of Physiology: Cell Physiology 2013304 C324-C333. (doi:10.1152/ajpcell.00337.2012)

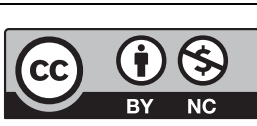

This work is licensed under a Creative Commons Attribution-NonCommercial 4.0 International License. 
104 Lingrel JB. The physiological significance of the cardiotonic steroid/ ouabain-binding site of the Na,K-ATPase. Annual Review of Physiology 201072 395-412. (doi:10.1146/annurev-physiol-021909-135725)

105 Dostanic I, Lorenz JN, Schultz Jel J, Grupp IL, Neumann JC, Wani MA \& Lingrel JB. The alpha2 isoform of Na,K-ATPase mediates ouabain-induced cardiac inotropy in mice. Journal of Biological Chemistry 2003278 53026-53034. (doi:10.1074/jbc.M308547200)

106 Dostanic I, Paul RJ, Lorenz JN, Theriault S, Van Huysse JW \& Lingrel $J B$. The $\alpha 2$-isoform of Na-K-ATPase mediates ouabain-induced hypertension in mice and increased vascular contractility in vitro. American Journal of Physiology: Heart and Circulatory Physiology 2005 288 H477-H485. (doi:10.1152/ajpheart.00083.2004)

107 Wansapura AN, Lasko VM, Lingrel JB \& Lorenz JN. Mice expressing ouabain-sensitive alpha1-Na,K-ATPase have increased susceptibility to pressure overload-induced cardiac hypertrophy. American Journal of Physiology: Heart and Circulatory Physiology 2011300 H347-H355. (doi:10.1152/ajpheart.00625.2010)

108 Dostanic-Larson I, Van Huysse JW, Lorenz JN \& Lingrel JB. The highly conserved cardiac glycoside binding site of Na,K-ATPase plays a role in blood pressure regulation. PNAS 2005102 15845-15850. (doi:10.1073/pnas.0507358102)

109 Lorenz JN, Loreaux EL, Dostanic-Larson I, Lasko V, Schnetzer JR, Paul RJ \& Lingrel JB. ACTH-induced hypertension is dependent on the ouabain-binding site of the alpha2-Na+-K+-ATPase subunit. American Journal of Physiology: Heart and Circulatory Physiology 2008295 H273-H280. (doi:10.1152/ajpheart.00183.2008)

110 Rindler TN, Lasko VM, Nieman ML, Okada M, Lorenz JN \& Lingrel JB. Knockout of the Na,K-ATPase alpha2-isoform in cardiac myocytes delays pressure overload-induced cardiac dysfunction. American Journal of Physiology: Heart and Circulatory Physiology 2013304 H1147-H1158. (doi:10.1152/ajpheart.00594.2012)

111 Correll RN, Eder P, Burr AR, Despa S, Davis J, Bers DM \& Molkentin JD. Overexpression of the $\mathrm{Na}+/ \mathrm{K}+$ ATPase alpha2 but not alpha1 isoform attenuates pathological cardiac hypertrophy and remodeling. Circulation Research 2014114 249-256. (doi:10.1161/CIRCRESAHA.114.302293)

112 Yazaki Y, Tsuchimochi H, Kurabayashi M \& Komuro I. Molecular adaptation to pressure overload in human and rat hearts. Journal of Molecular and Cellular Cardiology 198921 91-101. (doi:10.1016/00222828(89)90775-X)

113 Wang JM, Tan J \& Leenen FHH. CNS blockade by peripheral administration of AT1R blockers. Journal of Cardiovascular Pharmacology 200341 593-599. (doi:10.1016/0022-2828(89)90775-X)

114 Liang B \& Leenen FHH. Prevention of salt induced hypertension and fibrosis by $\mathrm{AT}_{1} \mathrm{R}$ blockers in Dahl $\mathrm{S}$ rats. Journal of Cardiovascular Pharmacology 200851 457-466. (doi:10.1097/ FJC.0b013e318169e948)

115 Leenen FHH \& Yuan B. Prevention of hypertension by irbesartan in Dahl S rats relates to central $\mathrm{AT}_{1}$ receptor blockade. Hypertension 200137 981-984. (doi:10.1161/01.HYP.37.3.981)

116 Krum H, Lambert E, Windebank E, Campbell DJ \& Esler M. Effect of angiotensin II receptor blockade on autonomic nervous system function in patients with essential hypertension. American Journal of Physiology: Heart and Circulatory Physiology 2006290 H1706-H1712. (doi:10.1152/ajpheart.00885.2005)

117 Raheja P, Price A, Wang Z, Arbique D, Adams-Huet B, Auchus RJ \& Vongpatanasin W. Spironolactone prevents chlorthalidone induced sympathetic activation and insulin resistance in hypertensive patients. Hypertension 201260 319-325. (doi:10.1161/ HYPERTENSIONAHA.112.194787)

118 Balavoine F, Azizi M, Bergerat D, de Mota N, Patouret R, Roques B \& Llorens-Cortes C. Randomized double-blind, placebo-controlled, dose escalating Phase I study of QGC001, a centrally acting aminopeptidase a inhibitor pro-drug. Clinical Pharmacokinetics 2014 53 385-395. (doi:10.1007/s40262-013-0125-y)

119 Bodineau L, Frugiere A, Marc Y, Inguimbert N, Fassot C, Balavoine F, Roques B \& Llorens-Cortes C. Orally active aminopeptidase A inhibitors reduce blood pressure: a new strategy for treating hypertension. Hypertension 200851 1318-1325. (doi:10.1161/ HYPERTENSIONAHA.107.098772)

120 Marc Y, Gao J, Balavoine F, Michaud A, Roques BP \& Llorens-Cortes C. Central antihypertensive effects of orally active aminopeptidase A inhibitors in spontaneously hypertensive rats. Hypertension 201260 411-418. (doi:10.1161/HYPERTENSIONAHA.112.190942)

121 Francis J, Weiss RM, Wei SG, Johnson AK, Beltz TG, Zimmerman K $\&$ Felder RB. Central mineralocorticoid receptor blockade improves volume regulation and reduces sympathetic drive in heart failure. American Journal of Physiology: Heart and Circulatory Physiology 2001 281 H2441-H2551.

122 Menon DV, Arbique D, Wang Z, Adams-Huet B, Auchus RJ \& Vongpatanasin W. Differential effects of chlorthalidone versus spironolactone on muscle sympathetic nerve activity in hypertensive patients. Journal of Clinical Endocrinology and Metabolism 200994 1361-1366. (doi:10.1210/jc.2008-2660)

123 Wray DW \& Supiano MA. Impact of aldosterone receptor blockade compared with thiazide therapy on sympathetic nervous system function in geriatric hypertension. Hypertension 201055 1217-1223. (doi:10.1161/HYPERTENSIONAHA.109.147058)

124 Huang BS \& Leenen FHH. The brain renin-angiotensin-aldosterone system: a major mechanism for sympathetic hyperactivity and LV remodeling and dysfunction post MI. Current Heart Failure Reports 20096 81-88. (doi:10.1007/s11897-009-0013-9)

125 Huang BS, Chen A, Ahmad M, Wang HW \& Leenen FHH. Mineralocorticoid and angiotensin II type 1 receptors in the paraventricular nucleus contribute to sympathetic hyperactivity and cardiac dysfunction in rats post myocardial infarction. Journal of Physiology 2014592 3273-3286. (doi:10.1113/jphysiol.2014.276584)

126 Lal A, Veinot JP \& Leenen FHH. Critical role of CNS effects of aldosterone in cardiac remodeling post-myocardial infarction in rats. Cardiovascular Research 200464 437-447. (doi:10.1016/j. cardiores.2004.08.004)

127 Huang BS, Ahmad M, Tan J \& Leenen FHH. Sympathetic hyperactivity and cardiac dysfunction post MI: different impact of specific CNS versus general $\mathrm{AT}_{1} \mathrm{R}$ blockade. Journal of Molecular and Cellular Cardiology 200743 479-486. (doi:10.1016/j. yjmcc.2007.07.047)

128 Huang BS, Ahmad M, Tan J \& Leenen FHH. Chronic central versus systemic blockade of $\mathrm{AT}_{1}$ receptors and $\mathrm{LV}$ dysfunction in rats post myocardial infarction. American Journal of Physiology: Heart and Circulatory Physiology 2009297 H968-H975. (doi:10.1152/ajpheart.00317.2009)

129 Yan X, Price RL, Nakayama M, Ito K, Schuldt AJ, Manning WJ, Sanbe A, Borg TK, Robbins J \& Lorell BH. Ventricular-specific expression of angiotensin II type 2 receptors causes dilated cardiomyopathy and heart failure in transgenic mice. American Journal of Physiology: Heart and Circulatory Physiology 2003285 H2179-H2187. (doi:10.1152/ ajpheart.00361.2003)

130 Hoffman S, Krause T, van Geel PP, Willenbrock R, Pagel I \& Pinto YM. Overexpression of the human angiotensin II type 1 receptor in the rat heart augments load induced cardiac hypertrophy. Journal of Molecular Medicine 200179 601-608. (doi:10.1007/s001090100246)

131 Pocock S, Wilhelmsen L, Dickstein K, Francis G \& Wittes J. The data monitoring experience in the MOXCON trial. European Heart Journal 200425 1974-1978.

Received in final form 24 July 2017

Accepted 30 August 2017

Accepted Preprint published online 30 August 2017

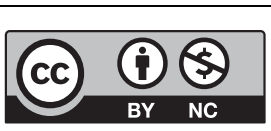

